\title{
Review Essay: China and the Internet: A Question of Politics or Management?
}

\section{Christopher R. Hughes}

You've Got Dissent: Chinese Dissident Use of the Internet and Beijing's Counter-Strategies. By MichAEL CHASE and JAMES MUlvenON. [Santa Monica, CA: RAND, 2002. xviii + 116 pp. ISBN 0-83303179-1.]

Open Networks Closed Regime: The Impact of the Internet on Authoritarian Rule. By Shanthi Kalathil and TAYlor C. BoAs. [Washington, DC: Carnegie Endowment for International Peace, 2003. $\mathrm{xii}+204$ pp. \$18.95. ISBN 0-870003-194-5.]

Lianxiang jituan chuanji 18 nian (The 18-Year Saga of the Legend Group). By Song HuAIJANG. [Taipei: Zhixun yinhang, 2002.]

Ehua budui: weilai guofang wuli (Informatized Army: Future Defence Force). By Li Anfu and Song BingGANG. [Taipei: Shiying chubanshe (Taiwan Elite), 2001.]

As take up of the Internet in China rises toward the 50 million mark, speculation concerning the social and political impact of this new technology on the authoritarian state has grown accordingly. While much of the earliest writing on the phenomenon tended to be of a journalistic bent, two recent reports from US-based think-tanks, RAND and the Carnegie Endowment for International Peace, attempt to take the field to a new level of sophistication. At the same time, the appearance of Chinese writing about the Internet from a variety of perspectives might provide material for broadening out the research agenda into new areas of sociological inquiry, and beyond the narrow question of whether the spread of Information and Communication Technologies (ICTs) leads to liberal political change.

Considering how so much of the belief in the potential of the Internet to transform authoritarian states has been encouraged by policy-makers rather than academics, the strength of both the RAND and Carnegie reports lies in the way that they avoid the temptation to exaggerate the significance of dissident activity in cyberspace. Instead, they pay close attention to how the state deters and monitors the Internet through a combination of low-tech and hi-tech methods. In this respect, You've Got Dissent is somewhat the stronger of the two reports because it has enough space to go into detail, while Open Networks only dedicates one chapter to China. ${ }^{1}$ You've Got Dissent provides reasonably detailed accounts of how dissidents have been hauled before the authorities and accused of various activities; lists of the main regulatory principles that have been established to demarcate what is deemed to be acceptable activity; and an 
overview of the physical shutdowns of network resources that have occurred. Social scientists lacking in technological training should also be grateful for explanations of how methods of control actually work, such as the proxy server system and the blocking of email from dissident websites outside China. With regard to hacking, the reader is even told how to trace culprits back to the Ministry of Public Security in Beijing (pp. 74-76)! A list of addresses of dissident websites is contained in the appendix for those who wish to do some browsing for themselves.

Given Chase and Mulvenon's detailed description of the main practices of control and surveillance deployed by the state, however, it is rather mystifying why the report should finish on the optimistic note that "the scale of China's information-technology modernization would suggest that time is eventually on the side of the regime's opponents" (p. 89). Although the first half of the book deals with dissident activity in cyberspace, it provides no real evidence to suggest that this has been successful for political mobilization inside China. Most of the case studies are actually related to overseas groups, and the authors elsewhere describe how the state is able to block these from penetrating inside China proper. Sometimes links between domestic and overseas activities are merely implied. The demonstration organized by the falun gong in April 1999, for example, is juxtaposed with detailed descriptions of the movement's activities in cyberspace outside China's firewalls. But no real linkage between these two phenomena is established, other than a footnote citing a report in the Christian Science Monitor. It could be added that the possibility that the Internet played an important role in the 1999 demonstration does not seem to sit well with the report's own observations that most of the participants were elderly females, while 80 per cent of Internet users in China are under 35 years of age and 60 per cent are male. The frequent notes of optimism over the liberating potential of the Internet that pepper this text do not, therefore, really square with the evidence that is presented.

Perhaps, then, it is a good corrective to read You've Got Dissent in tandem with Open Networks, because Kalathil and Boas actually set out to question the "conventional wisdom" that the Internet is a force for liberal political change in authoritarian states, by developing "a framework that allows for methodological thinking about limited evidence" (p. 3). The result is a much broader analysis, ordered under the categories of civil society, politics and the state, the economy and the international sphere. It is also a more sociological work in the way it locates the appropriation of the Internet both in the comparative context of other authoritarian states, and the specific cultural context of the nation-building project in China. The difference between the conclusions in this work and those reached in You've Got Dissent is indicated by the title of the final chapter, Beyond Blind Optimism.

The authors of Open Networks thus develop an argument that is both comparatively nuanced and cautious, effectively broadening the debate beyond issues of dissidents-versus-the-state and toward more complex issues concerning the relationship between technological and social 
change by highlighting a number of important issues. How, for example, can bureaucratic organizations be developed to build and police the Internet, while competition is introduced into the IT sector to make it internationally competitive at the same time? How can the state maintain control while informatization be used to boost economic development, improve administrative efficiency, address the digital divide between the eastern and western provinces? And how can national security be maintained while foreign technology and know-how are adopted on a large scale? Within these dynamics, important signs of change can be seen, such as the erosion of the State Administration of Radio, Film and Television's (SARFT) monopoly on news information caused by the turf war between the MII and SARFT due to broadband convergence. Similarly, the authors acknowledge the existence of government officials who see informatization as "changing the very scope and structure of government processes" (p. 24). Yet they are also careful to emphasize that change does not necessarily mean democratization, as indicated by the high salience of nationalistic activity in Chinese cyberspace.

If Open Networks is effective in questioning the conventional wisdom, though, the fact that its coverage of China is confined to one chapter makes it rather limited for country specialists and for those interested in the sociology of technology. It is also somewhat puzzling that the authors should feel the need to state that "little attention has been paid to the issue in academia" (p. 3) when their work does in fact owe much to the sizeable body of academic literature that has already appeared on the subject of the Internet in China and the sociology of ICTs in general. In fact, the movement away from technological determinism took place several years ago in Internet studies, as the panoply of methods available for the state to stage its counter-revolution began to emerge. Given the large number of international agreements on data sharing and electronic surveillance to which most states in the world have signed up since 11 September 2001, or the uncertain fate of the CIA sponsored Triangle Boy project (which was supposed to provide Internet users in authoritarian states with online anonymity), the issue of regulating cyberspace is certainly more pressing than that of using it to bring about regime-change - especially for policy-makers. Give or take a few terrorists, child pornographers or money launderers, does anybody still believe that a completely unregulated Internet is a desirable thing?

Despite such developments, however, seminal works such as Boyle's application of the Foucauldian Panopticon concept to explain the culture of self-surveillance in cyberspace, ${ }^{2}$ or Lessig's arguments concerning whether it is possible to regulate cyberspace, ${ }^{3}$ are either not mentioned or just touched on in passing. Considering that Kalathil and Boas wish to critique the "conventional wisdom" that the Internet undermines authori-

2. James Boyle, "Foucault in cyberspace: surveillance, sovereignty, and hard-wired censors," posted online 1997, http://www.wcl.american.edu/pub/faculty/boyle/foucault.htm (accessed 6 November 2000).

3. Lawrence Lessig, Code and Other Laws of Cyberspace (New York: Basic Books, 1999). 
tarian regimes, they could also have been more critical of the motives of the policy-makers from whom such a view has originated by drawing on the work of writers like Ethan Kapstein. ${ }^{4}$ However, although Kalathil and Boas do not really come to grips with such issues, they do touch on a number of important areas of research that have been developed in Internet studies and pose enough questions to indicate a rich agenda for future research.

A good example of one such issue is the relationship between the state, Chinese commercial Internet firms and foreign firms under WTO rules. This is raised when Kalathil and Boas mention the partnership that has been established between AOL-Time Warner and Legend, China's top PC manufacturer. To gain further insight into such issues, it might be useful to begin to draw on some of the Chinese literature concerning the Internet that is now appearing in abundance. A good example is Lianxiang jituan chuanji 18 nian, the popular biography of Liu Chuanzhi, former president and managing director of Legend Computers, by Song Huaijiang, a doctoral graduate of Beijing University. Here the links between private enterprise and the state are laid out fairly clearly. The firm was established in 1984 with funding from CAS, and quickly achieved a domestic monopoly on the technology for inputting and displaying Chinese characters. With the CAS name behind it, Legend was able to raise funds in Hong Kong to enter the international OEM market in 1988. In 1994, CAS came to the rescue again by providing a new injection of cash to allow Legend to keep up with the IT boom. The firm plays a faithful role in return, having taken a lead in building the infrastructure that makes possible the state's plans for e-government and e-commerce. When the firm launched its global Internet strategy in 1999, it chose the ancient capital city of Xi'an for the opening ceremony, indicating its commitment to the project of linking the whole of China to the globalization process (p. 228).

The most interesting aspect of biographical literature, though, is what it tells the reader about the character or the main subject. It is not hard to see why Liu should have been considered to be the right person to play the leading role in Legend. Born in 1944, he received his original training at the Military Telecommunications Academy in 1961-67, then spent a year carrying out defence-orientated research in Chengdu. He moved on to CAS in 1970, after his Cultural Revolution spell of agricultural labour at Zhuhai, Guangdong (p. 278). When Liu was selected to establish and lead the new firm, he was stationed in the cadre section of CAS. By March 1998 he had been appointed to the National People's Congress. In short, Liu and his enterprise have been cultivated by the state so that Legend can become a member of China's National Team of very large enterprises fit for competition in the global market.

It is not surprising then that Liu's management jargon is fully in tune with the state's nation-building project. He sums up a vision of his firm's 
development from small enterprise through national enterprise to global corporation using militaristic metaphors, such as moving through the three stages of "speedboat mode, ship structure, flotilla mode" ("ping di kuai chuan moshi, da chuan jiegou, jiandui moshi”) (p. 75-79). Similarly, his "Three Factors of Management," namely "organize the troops, fix the strategy, lead the team" (zuzhi tuandui, ding zhanlue, dai duiwu), is reminiscent of the slogans imposed on his generation by decades of political indoctrination. Lenin himself would not have blushed at the idea of building a core of leaders who share common ideals, unite to co-operate and possess the strength to engage in "struggle." Mao might well have recognized the call to "fix the strategy" by calling on cadres at all levels to be aware of the general situation, consider the long-term, then break down the main objectives into particular tactics while always being able to adapt. Deng Xiaoping would have approved of "leading the team" by creating a special culture for the enterprise, consolidating the strength of its personnel, creating an atmosphere of professionalism, cultivating leaders and establishing a firm base for the future. He would also have approved of Liu's belief that his thinking is distinct from foreign management theory due to its emphasis on collective leadership, consensus building and the need to enter into a kind of contract with the firm to prevent the extremes that might arise from either individual leadership or factionalism (pp. 68-70).

If Liu Chuanzhi's story provides interesting insights into the politicization of management theory in the Chinese commercial ICT sector, Ehua budui: weilai guofang wuli, a report on military training by two Taiwanese experts on military affairs, Li Anfu and Song Binggang, illustrates what happens when informatization leads managerialism to impact on military doctrine. While much of this work is an exhaustive technical account of the impact of ICTs on military doctrine that is framed mainly in the standard literature on the Revolution in Military Affairs (RMA), the fifth chapter is most interesting from a sociological point of view because it deals with the problem of adapting military education and training during an era of very rapid technological transition. In doing so, the authors divide their subject into sections that deal with the need to make changes to ideas, modes of operation, system building, and cultural and psychological factors.

When read alongside Song Huaijiang's book, however, a striking irony emerges as it becomes apparent that military thinkers in Taiwan propose that they can meet the demands of the information revolution by using management theory, while a Chinese entrepreneur like Liu Chuanzhi believes that he can manage his business according to pithy slogans reminiscent of CCP propaganda. While Liu envisions his flotilla sailing out into the world, Li and Song see the armed forces structuring themselves like commercial enterprises that constantly renew themselves in order to survive in the global marketplace. Whereas Liu sees his troops advancing under a collective leadership with himself at the core, Li and Song look to Organizational Behaviour theory ${ }^{5}$ to strike the optimal 
balance between hierarchy and levelling out, face the conflicts imposed when the art of strategy clashes with the nature of technology, to establish a workable relationship between collectivist ideals and individualism, and to maintain the continuity of organizations as they go through different stages of restructuring.

Perhaps what is seen in these two books, then, is some kind of erosion of the barriers between militaristic and commercial thinking as different social sectors turn to managerial thinking as they try to address the growing dependence of organizations on knowledge as a resource and a commodity. The predicaments faced in both sectors are indeed pressing. $\mathrm{Li}$ and Song illustrate this by citing the examples of Middle Eastern armies that have acquired high technology weaponry only to discover that they do not have competent personnel to operate it (p. 271). They find the answer in the establishment of a US-style School of Information Warfare and Strategy, and having training systems focusing on long, medium and short-range scenarios, co-ordinated like the hands of a wristwatch (p. 277). Liu Chuanzhi, meanwhile, wonders how to foster and retain creative personnel in a mobile labour market with increasing foreign competition for talent. His answer is to combine recognition and reward of individual talent with collective leadership and an appeal to patriotic and selfless values.

The common problem that unites military and business managers most of all is the way in which their growing dependence on technological expertise gives an unprecedented degree of power and status to young professionals in both the military and civilian sectors. Liu Chuanzhi laments the loss of the ideals of honesty, seeking glory, hard work, thrift and patriotism, that were characteristic of the firm's founding generation. Although the Spartan spirit is still supposed to be at the core of Legend's value system, Liu cannot help but complain about the decline of collectivist values that began to take place when Legend started to recruit personnel from sources other than CAS back in 1988. Members of this new generation, mainly in their thirties, were more interested in seeking their own personal glory, were already accustomed to good working conditions and were fully aware that they could take up other job opportunities if they were not satisfied with the treatment they received at Legend. He reminds the new generation of employees that the greater part of what they produce should go back to their country, because without the CAS name behind it, his firm would never have even broken into the OEM market let alone grown to its present size.

$\mathrm{Li}$ and Song, on the other hand, grapple with the problem of how to restructure a hierarchical system in which the senior ranks are technologically illiterate in comparison with their subordinates. They find the answer in the idea of "popularized defence" ("guofang shiwu quanminhua"), which means integrating the civilian and defence industries in ways that both maximize the cross-fertilization of technologies and allow individuals to develop talents that can develop their own professional careers in the civilian sector while meeting the requirements of the military when they are called on. Again, the organizational answer is to 
be found in management theory, which addresses the need for enterprises to constantly remake themselves to survive, although $\mathrm{Li}$ and Song accept that this kind of constant remaking of the rules will be harder to adjust to for Asian societies with collectivist cultures derived from their agricultural mode of life (pp. 299-300).

Of course, viewing such issues through the eyes of management theory is one way to try to depoliticize what are ultimately highly sensitive political issues generated by the impact of ICTs. While most of these are closely related to the fate of the authoritarian state that is discussed in works like You've Got Dissent and Open Networks, they also cause much wider waves, which have to be incorporated into the social science research agenda. While Open Networks makes a good attempt to develop such a new agenda, ultimately it is still somewhat limited by the self-imposed task of its authors to question the conventional wisdom. Perhaps both academics and policy-makers have already moved on to more complex issues, and asking whether the Internet is a force for liberalization is now no more appropriate as a question to guide research than is asking whether the printing press is a force for liberalization. The answer for both is yes and no, depending on how the technology is appropriated by any particular society. As some of the new Chinese literature indicates, there are also many other phenomena generated by the impact of ICTs in China that are worth studying. 